\title{
Factors related to the quality of the home environment and children's achievement
}

\begin{abstract}
This study tested Belsky's model of the determinants of parenting. Using data from the National Longitudinal Survey of Youth (NLSY), the study focused on 898 mothers (African Americans, $\mathrm{n}=347$; Caucasians, $\mathrm{n}=551$ ) and their 6- to 8-year-old children. Consistent with Belsky's model, mothers who provided better quality home environments had higher levels of education, intelligence, and self-esteem. Mothers with higher family incomes, fewer children, and higher marital quality provided more supportive home environments. In addition, age and gender of the children were significantly related to the quality of the children's home environments. Additional analyses indicated that the quality of the home environment that mothers of both ethnic groups provided was related to their children's achievement.
\end{abstract}

Keyword: Belsky's model; Home environment; Children's achievement 